\title{
Multiple cervical spondylolisthesis and thoracic vertebral malformation in an 11 month-old Chilean Caballo Raza Chilena colt
}

\author{
Cristóbal Dörner ${ }^{\mathrm{a}, \mathrm{b}^{*}}$, Javiera Encalada ${ }^{\mathrm{b}}$, Jorge Maldonadoc ${ }^{\mathrm{c}}$ Joanie Palmero $^{\mathrm{d}}$
}

\begin{abstract}
Compressive myelopathy caused by developmental cervical and thoracic malformation was diagnosed in an 11-monthold Chilean Caballo Raza Chilena colt. The patient evidenced an abnormal wide-based stance, neck muscle atrophy, upside-down neck conformation and tetra ataxia. Ataxia was exacerbated when the colt was walked down and uphill, walked with elevated head, backing and turning in tight circles. The patient showed no improvement following medical therapy, therefore, the colt was euthanised due to a poor prognosis after myelogram findings. Cervical spine malalignment (spondylolisthesis) associated with multi-level compression of the spinal cord was suspected based on cervical radiographs and myelogram findings and was confirmed postmortem. Thoracic vertebral malformation retained cartilage matrix spicules and a flare of the cranial vertebral epiphysis of the first thoracic vertebrae (T1) were also diagnosed at necropsy.

Key words: horse, cervical vertebrae, stenosis, myelogram.
\end{abstract}

Cervical vertebral malformation (CVM) (also known as cervical vertebral compressive myelopathy, wobbler syndrome and cervical stenotic myelopathy) (Reed et al 2007, Cardona et al 2013, Kühnle et al 2018, Szklarz et al 2019) is a common and widely described cause of ataxia and paresis affecting many different breeds of horses (Levine et al 2010). Ataxia and weakness commonly seen in horses with CVM are caused by narrowing of the cervical vertebral canal and compression of the spinal cord, often combined with malalignment and malformation of the cervical vertebrae. Two broad categories of CVM resulting in spinal cord compression have been proposed; type 1 affects young horses with compression as a result of developmental abnormalities of the cervical vertebral column, and type 2 affects older horses and typically involves a degenerative process (Nout and Reed 2003, Reed et al 2007).

The most important factor in the diagnosis of cervical vertebral malformation in adult horses and foals is the identification of cervical vertebral canal stenosis. The diagnosis can be made with more confidence by assessing the diameter of the vertebral canal. In many cases, cervical radiographs and myelography remain the only tools available to confirm a diagnosis of CVM and to define the site of spinal cord compression. Myelography has been considered the gold standard antemortem diagnostic test, however, sagittal diameter ratio analysis from plain

Received: 08.03.2021.

Accepted: 02.09.2021

${ }^{a}$ Escuela de Medicina Veterinaria, Facultad de Recursos Naturales y Veterinaria, Universidad Santo Tomás, Viña del Mar, Chile.

${ }^{\mathrm{b}}$ Equestria Equine Medical Center, Región de Valparaíso, Quillota, Chile. ${ }^{c}$ Equine Practitioner, Tiltil, Chile.

${ }^{\mathrm{d}}$ Equine Practitioner, Diplomate of the American College of Veterinary Internal Medicine-LA, California, USA.

*Corresponding author: C Dörner; Fundo el Castaño lote 8, Lo Mardones, Quillota, Chile; cdorner@gmail.com radiographs may be more sensitive and specific than myelography and use of intra- and intervertebral sagittal diameter ratios may have greater predictive accuracy for diagnosis of CVM (van Biervliet et al 2006, Reed et al 2007, Hahn et al 2008). Although CVM is known to affect many different breeds of horses (i.e. described in $1.3 \%$ of young Thoroughbreds (Oswald et al 2010)) it is a condition rareley diagnosed in young and adult horses Caballo Raza Chilena and accordingly, there is no reference in the equine literature describing CVM in this breed.

The etiopathogenesis of breed predilections of CVM is still unknown but is speculated to involve genetic factors and differences in both morphometry and use. The Caballo Raza Chilena breed is characterised by a muscled short neck conformation and, furthermore, their late taming results in maintenance nutrition at younger ages avoiding overfeeding when compared to other breeds (Murúa 2006). All the above might be important factors involved in the low incidence of CVM reported in this breed. This case report describes severe cervical and thoracic malformation in an 11-month-old Caballo Raza Chilena with clinical features that, to the authors' knowledge, have not been previously described for this breed.

An 11-month-old Caballo Raza Chilena was presented to the referral hospital with progressive onset of neurologic signs, including severe ataxia of all 4 limbs. At 6-monthsold, the owner noticed a ewe-necked conformation showing an upside-down neck, the development of intermittent stumbling and an abnormal stance. Clinical signs persisted until the colt was referred to the veterinary hospital. No known history of trauma was reported. Vaccination and deworming status were up to date. Diet consisted of alfalfa hay and water ad libitum and was deemed adequate.

At initial presentation, the colt was bright, alert, and responsive with normal vital parameters and a body condition score of 4 (range 1-9) (Henneke et al 1983). The colt was grade $3 / 5$ ataxic in all 4 limbs with normal mentation and behaviour (Reed et al 2007). Static neurological 
Table 1. Sagittal diameter ratios and myelographic measurements for vertebral sites of the colt with cervical vertebral malformation.

\begin{tabular}{lcccc}
\hline Localisation & $\begin{array}{c}\text { Intervertebral } \\
\text { ratio }\end{array}$ & $\begin{array}{c}\text { Intravertebral } \\
\text { ratio }\end{array}$ & $\begin{array}{c}\text { Dorsal column } \\
\text { diameter reduction }\end{array}$ & $\begin{array}{c}\text { Ventral column diameter } \\
(\text { VB) }\end{array}$ \\
\hline C2-C3 & $88.35 \%$ & C3 $55.85 \%$ & $18 \%$ & $\mathrm{C} 3=3.49 \mathrm{~mm}$ \\
C3-C4 & $70.81 \%$ & C4 $55.50 \%$ & $9.4 \%$ & $\mathrm{C} 4=3.54 \mathrm{~mm}$ \\
C4-C5 & $74.39 \%$ & $\mathrm{C} 553.39 \%$ & $93.61 \%$ & $\mathrm{C} 5=0 \mathrm{~mm}$ \\
C5-C6 & $76.38 \%$ & $\mathrm{C} 658.14 \%$ & $89.8 \%$ & $\mathrm{C} 6=3.65 \mathrm{~mm}$ \\
C6-C7 $*$ & $72.67 \%$ & $\mathrm{C} 763.18 \%$ & - & $\mathrm{C} 7=4.25 \mathrm{~mm}$ \\
C7-T1 & $86.40 \%$ & T1 $59.74 \%$ & - & $\mathrm{T} 1=3.78 \mathrm{~mm}$ \\
\hline
\end{tabular}

*Dorsal column diameter reduction and dural diameter reduction were not obtained because the dorsal contrast column was lost at C6-C7.

exam revealed abnormal (base-wide) limb posture, neck muscle atrophy (cervical serratus, rhomboid, and splenius muscles), ventral displacement of the cervical vertebrae and trachea, and low head carriage (figure 1A). No cranial nerve deficits were observed. Gait analysis showed a severe lack of coordination of motor movements in all four limbs. Ataxia was exacerbated when the colt was walked down and uphill, walked with the head elevated, backing, and turning in tight circles. The colt also showed signs of brachial plexus compression during certain manoeuvres, became stiff in the front limbs, and almost dropped. Dynamic tail pull showed a lack of resistance, and the hind limbs were weak and easily pulled off balance followed by the colt taking several strides to recover.

The colt was treated with flunixin meglumine ${ }^{1}(1 \mathrm{mg} / \mathrm{kg}$ bwt i.v b.i.d.), dexamethasone ${ }^{2}(0.01 \mathrm{mg} / \mathrm{kg}$ bwt i.v s.i.d.), dimethylsulfoxide $99 \%^{3}$ (100 mL in 1 L Lactated Ringer's solution ${ }^{4}$ ) i.v. s.i.d., during 4 days. Despite treatment, no improvement was observed, and the colt was referred to the veterinary hospital for further diagnostics including imaging.

Complete blood count and serum biochemistry profile were unremarkable. Standing cervical radiographs showed severe malalignment (ventral subluxation) of the cervical vertebral column between $\mathrm{C} 4-\mathrm{C} 7$, but no narrowing of the vertebral canal was noted (figure1B, table 1). A myelogram was subsequently performed under intravenous anaesthesia in a padded recovery room as described by Grant and Paterson (2006) (figure 2). An 18G spinal needle was placed in the atlantooccipital space, $40 \mathrm{~mL}$ of cerebrospinal fluid (CSF) were withdrawn, and $40 \mathrm{~mL}$ of contrast agent (iodixanol [Visipaque 300$]^{5} 300 \mathrm{mg} / \mathrm{mL}$ ) were injected intrathecally.

\footnotetext{
1 Febrectal $^{\mathrm{TM}}$, Dragpharma, Santiago, Chile.

2 Hasyun $^{\mathrm{TM}}$, Dragpharma, Santiago, Chile.

3 DMSO 99\%, Valhoma, Tulsa, OK.

4 Ringer-Lactato, Baxter Chile, Santiago, Chile.

5 Visipaque $^{\mathrm{TM}}$ 300, GE Healthcare Inc. Chile, Princeton, NJ.
}

The myelogram revealed spinal cord compression in neutral, flexed, and extended radiographs at C5 (loss of ventral dye column within the vertebral body), between C5-C6 (thin dorsal column), and between C6-C7 (loss of dorsal dye column) (table 1). Contrast material was observed until caudal T1 (figure 3). No thoracic abnormalities of bone were presumed from plain radiographs nor myelogram. Based on these findings, developmental cervical vertebral malformation/malarticulation (spondylolisthesis) was diagnosed.

The colt recovered uneventfully from the myelogram. However, due to the myelographic findings of vertebral canal stenosis, multiple areas of spinal cord compression, and associated poor prognosis, euthanasia and postmortem evaluation were elected. At necropsy, malformation of the dorsal lamina of $\mathrm{C} 5$ and $\mathrm{C} 7$ were observed causing stenosis of the vertebral canal. Additionally, thoracic vertebral malformation associated with retained cartilage matrix spicules and a flare of the cranial vertebral epiphysis of the first thoracic vertebrae (T1) were also diagnosed at necropsy. Spinal cord histopathology was not performed, and no other organs were examined postmortem.

Compressive stenotic myelopathy is the most common non-infectious cause of spinal ataxia in young and adult horses (Levine et al 2010, Janes et al 2015). The first type of CVM occurs in young horses and is essentially developmental in which malformation/malarticulation of the cervical vertebral column causes spinal cord compression (van Biervliet et al 2006). Compressive vertebral malformation in young horses $(<3$ years old) is a multi-factorial disease affected by genetic predisposition and environmental influence such as gender, nutrition, hormonal changes, exercise, trauma, and rate of growth (van Biervliet et al 2006, Levine et al 2008), with Thoroughbreds and Warmbloods being overrepresented (Levine et al 2010, Piercy 2011). Different types of lesions have been reported in young horses (osteochondrosis, osseous cyst-like structures, fibrous tissue replacement of trabecular bone, retained cartilage matrix spicules, and osteosclerosis) providing evidence that developmental abnormalities during cervical vertebrae growth and 


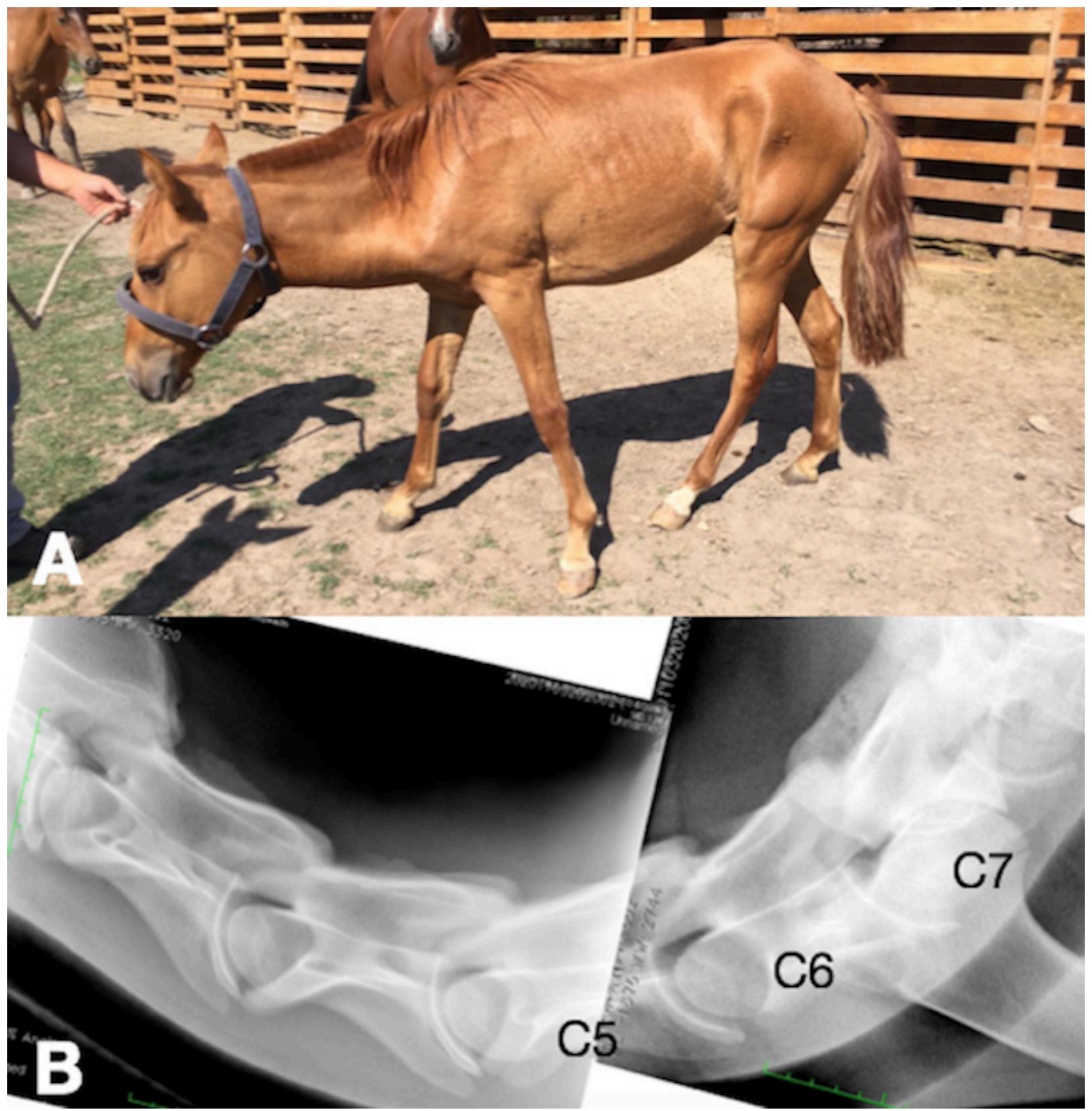

Figure 1. A) Photograph of the colt presenting a notorious alteration at mid and lower neck with low head carriage, abnormal stance in the fore and hind legs and muscle atrophy of the neck. B) Reconstruction of the colt cervical radiographs in neutral position showing malalignment (spondylolisthesis) most evident between C4-C5 and C6-C7 without apparent intervertebral space abnormalities.

maturation are important in their pathogenesis (Stewart et al 1991, Janes et al 2015, Bergmann et al 2020). Also, anomalous C6 with absence (symmetric or asymmetric) of the ventral lamina of the transverse process might be associated with developmental spinal stenosis (DeRouen et al 2016). The second type of CVM is most often seen in mature horses and has been commonly characterised by malformation with degenerative joint disease of the articular processes, wedging of the vertebral canal, periarticular proliferation with or without a synovial or epidural cyst and overt fractures of the articular processes (Reed et al 2007). Spinal cord compression may also result from traumatic injury (Matthews and Nout 2004, Denoix 2005), vertebral body fracture (Matthews and Nout 2004), vertebral neoplasia (Hirsch et al 2009), discospondylitis (Furr et al 1991, Denoix 2005), intervertebral disk protrusion (Nixon et al 1984), epidural hematoma (Cunha dos Santos et al 2014, MacMillan et al 2020), ischemic fibrocartilaginous embolism (Sebastian and Giles 2004, Dörner et al 2015) and arachnoid diverticulum (Allison and Moeller 2000). Furthermore, spinal cord compression may be also associated to congenital malformations such as hemivertebrae (Wong et al 2005), butterfly vertebrae (Rendle et al 2008), block vertebrae (Perris et al 1994), occipitoatlantoaxial malformation (Mayhew et al 1978, Watson and Mayhew 1986), atlantoaxial subluxation (Witte et al 2005) and atlantoaxial instability (Rush 2012, Cole et al 2017). However, congenital anomalies of the vertebral column are reported infrequently. In Chile, as elsewhere, CVM is a disease commonly diagnosed in young and adult Thoroughbreds and Warmbloods. Despite being the most prevalent cause of spinal ataxia in the abovementioned breeds, CVM is rarely noted in young and adult Chilean horses and thus has not been described in the literature in 


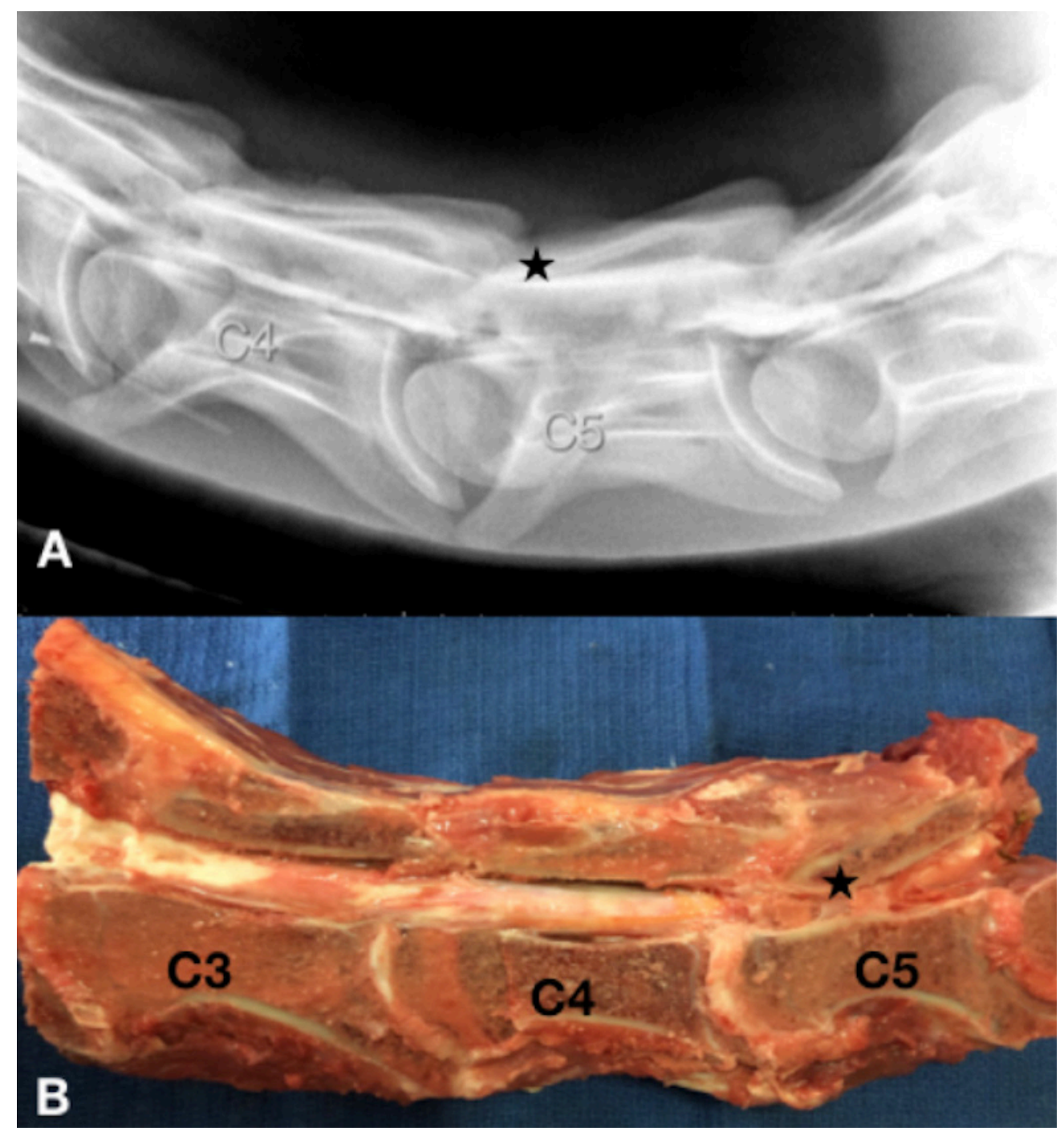

Figure 2. A) Contrasted cervical radiographs with neck in neutral position showing complete loss of the ventral dye column at C5. B) Anatomical dissection with longitudinal cross section of the C3-C5 cervical spine showing the site of spinal cord compression at C5 (black star).

this breed until today. The Caballo Raza Chilena horses are characterised by a lower growth rate and a muscled short neck conformation when compared to other breeds. It has been previously described that both rapid growth rates and length of the neck could be influencing the development of CVM (Rooney 1969, Levine et al 2008). Also, late taming and the start of training at approximately the age of 3 for this breed (Murúa 2006) results in a maintenance diet without overnutrition. All these factors could be involved in the low incidence of CVM in this breed.

In this case, the colt manifested classic signs of cervical spine impingement associated with ventral subluxation, also referred to as spondylolisthesis (Denoix et al 2005, Denoix 2007, Dyson et al 2020) between C4-C7. Also, a bony formation in the dorsal laminae of $\mathrm{T} 1$, probably as a result of retained cartilage matrix spicules (Janes et al 2015), along with a flare of the cranial vertebral epiphysis of T1 was noticed postmortem. Spondylolisthesis refers to a displacement of one vertebra on another (Denoix 2007) and it has been identified with transrectal ultrasonographic examination at the lumbosacral junction in adult horses (Denoix et al 2005), in the atlantoaxial joint in foals (Witte et al 2005) and recently in the cervical and cranial thoracic vertebrae associated with intervertebral disk disease in adult horses (Dyson et al 2020). Although the attenuation of dye at T1 during myelogram was attributed to the typical loss of dye column at that level, it is possible that these malformations and associated suspected impingement impeded the dye from progressing farther caudally beyond $\mathrm{T} 1$.

We were not able to delineate a specific cause for the cervical and thoracic malformations encountered in this horse. Abnormal in-utero development or position during pregnancy might have played a role in the development 


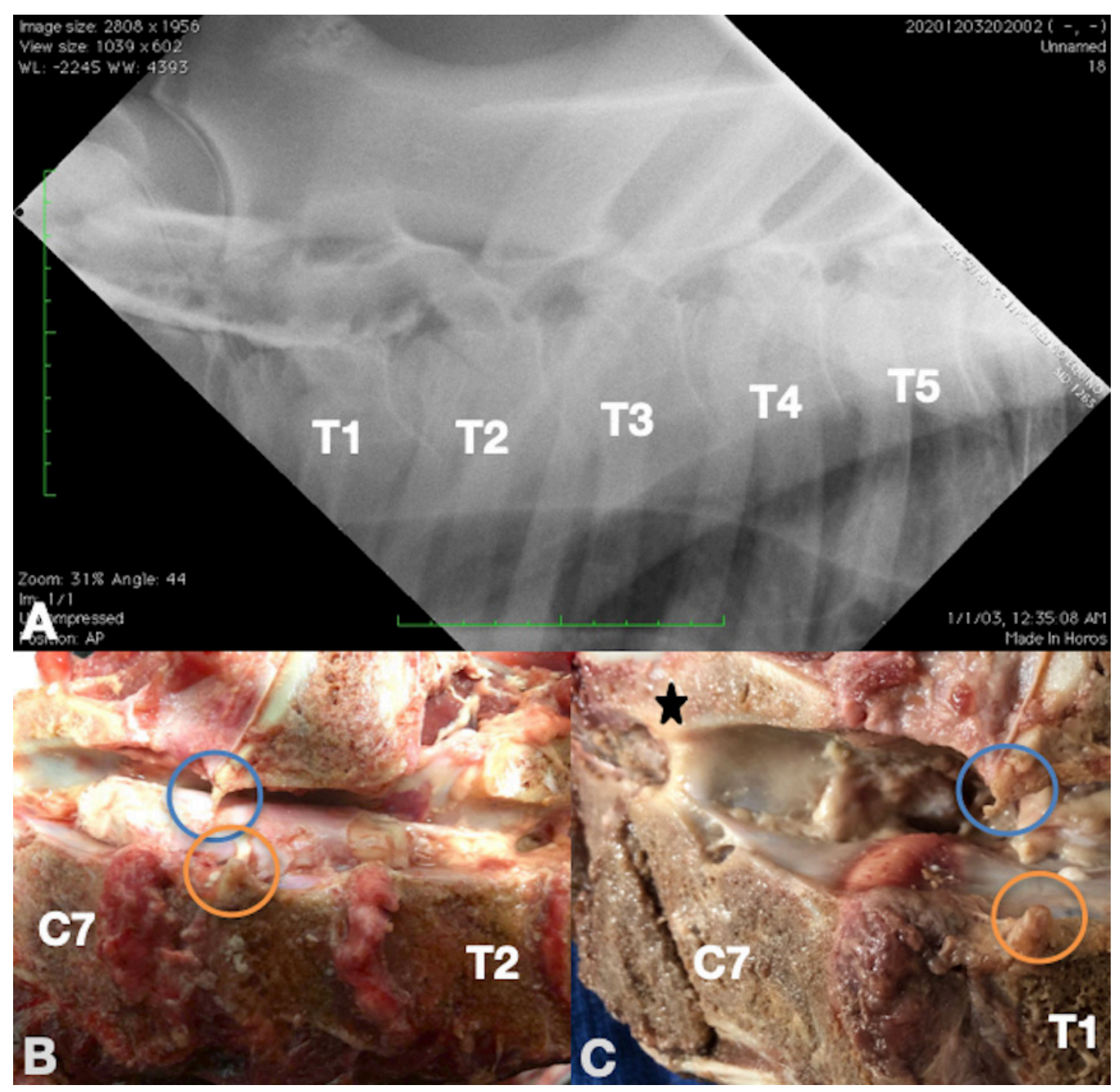

Figure 3. A) Radiograph taken during myelogram of proximal thoracic vertebrae (T1-T5). Contrast material is only observed until caudal T1. No thoracic abnormalities of bone were presumed from plain radiographs nor myelogram. B) Anatomical dissection with longitudinal cross section of the C7-T2 spine showing two large spicules, one in the cranial dorsal laminae of T1 (blue circle) and one in the cranial vertebral body of T1 (orange circle). C) Photograph showing spinal canal narrowing at C7 (black star) representing a second site of spinal cord compression.

of this condition, but neurologic deficits would have been expected to occur much earlier in the horse's life and no abnormalities were detected neither by the owner nor the field veterinarian before weaning. On the other hand, even though the diet was deemed adequate for this colt, it is not known to what extent trace nutrients, such as copper and zinc deficiencies, or calcium and phosphorus imbalance may have contributed to the presentation of the malformation observed in this horse. To our knowledge, there are no known calcium, phosphorus, copper, or zinc deficiencies in the area where the colt lived (Maldonado 2006). On the other hand, and even though blood and soil selenium concentrations were not measured, the south of Chile is characterised for being deficient in selenium (Crempien 1988, Tapia 2013) and as it is widely described that selenium is an essential microelement for animal development (Zarczyñska et al 2013, Hung Son and Duong Huyen 2019). However, similarly aged colts on the property, as well as direct relatives of the colt, were free from abnormalities. Despite the above, some degree of nutrient abnormality in the colt's diet cannot be ruled out nor can an underlying error of metabolism.

Radiographic indicators and measurements of the cervical canal height categorised by standard minimal sagittal diameter, and intravertebral and intervertebral ratios have been widely used despite the potential for false positive and false negative determinations of canal stenosis (Janes et al 2013). According to the above reference, spinal cord compression is possible if intra and intervertebral ratios are $>50 \%$ for C4, C5 and C6 or $>52 \%$ for C7 (Reed et al 2007), as shown in the colt presented in this case (table 1) in which the ratios were within normal parameters, but 
spinal cord compression was only evident via myelography. For this reason, diagnosing sites of compression may be more accurate when both sagittal diameter ratios and myelographic measurements are used together (Hahn et al 2008). Additionally, postmortem magnetic resonance studies have shown that vertebral canal area and cord canal area ratios are better parameters to predict the location of cervical canal stenosis than only the sagittal plane of canal height (Janes et al 2013).

An important aspect that should be considered from this report is that radiographs and myelography can certainly underestimate the severity of spinal cord compression (Gough et al 2020). There are still some abnormalities that cannot be definitively diagnosed with conventional nor contrasted radiographs. Computed tomography (CT), or magnetic resonance are the imaging modalities that can appraise more accurately sites of spinal cord compression, vertebral structures, or bone changes and can help to confirm a specific diagnosis (Janes et al 2015, Gough et al 2020). Unfortunately, these advanced imaging tools are not available in many practices. Therefore, intra- and intervertebral sagittal ratios, dural diameter and contrast column reduction measurements often remain the only tools available to diagnose, prognose and propose treatment despite the risk of false positives or false negatives (Janes et al 2013).

Neurological clinical signs associated with cervical spinal cord compression were very characteristic in this case and considering the exacerbation of the signs with specific maneouvres, dynamic compression was presumed following clinical examination. However, the myelogram did not show significant differences in dye column reduction between changes in neck positioning (neutral, flexed or extended). Although no dynamic compression was evident during the myelogram, attenuation, and loss of contrast columns within vertebral bodies were observed in multiple sites, hence a static compression at C5, C6 and C7 was deemed more likely. Furthermore, even though the spinal cord compression was diagnosed after the myelogram, the severity of compression was only evidenced after necropsy (figures 2 and 3). Additionally, necropsy revealed a significant spicule in the cranial aspect of the dorsal laminae of T1 along with a flare of the cranial vertebral body of T1, neither of which were visible in the radiographs (figure 3). Most cases of thoracolumbar malformations described in horses have been manifested as gross deformity, usually without associated spinal cord compression and ataxia, and they include mainly transitional abnormalities and vertebral axis deviations (Lerner and Riley 1978, Denoix 2005). Thoracic vertebrae malformation causing neurological signs has been described only in a few horses before (Johnson et al 1997, Rush 2012). Even though thoracic spinal compression was not initially suspected after the myelogram, after correlating the clinical signs and necropsy findings, it is possible that the attenuation of dye at $\mathrm{T} 1$ represented compression at that level. Spinal cord histopathology would have further characterised the extent of compression but unfortunately, was not performed.

Although surgical treatments have been reported (Nixon 1991, Moore et al 1993, Kühnle et al 2018, Pezzanite et al 2021), further procedures were foregone in this case, and euthanasia was selected due to imaging findings, severity of clinical signs and associated poor prognosis.

Cervical malformation with spinal cord compression and ataxia is a common cause of neurological deficits in young horses of various breeds, while neurologic signs associated with thoracic vertebral malformation have been rarely reported. To our knowledge, this is the first reported case of multiple cervical spondylolisthesis and thoracic vertebral malformation with associated multi-level cord compression in the Caballo Raza Chilena horse. Vertebral malformation and malalignment should be considered as differentials for ataxia and neurologic deficits in young horses, including this Chilean breed, even if not evident radiographically.

\section{ETHICAL STATEMENT}

The owner agreed to the presentation and divulgation of this case report.

\section{REFERENCES}

Allison N, Moeller Jr. R. 2000. Spinal ataxia in a horse caused by an arachnoid diverticulum (cyst). J Vet Diag Invest 12, 279-281.

Bergmann W, Mik-van Mourik M, Veraa S, van de Broek J, Wijnberg I, Back W, Gröne A. 2020. Cervical articular process joint osteochondrosis in Warmblood foals. Equine Vet J 52, 664-669.

Cardona J, Betancur C, Alvarez J. 2013. Síndrome de wobblers en un caballo. Rev MVZ Córdoba 18, 3411-3415.

Cole R, Taintor J, Hanson R. 2017. Atlanto-axial malformation in an adult Quarter horse gelding. Can Vet J 58, 923-925.

Cunha dos Santos F, de Lourdes Adrien Delgado M, Fernandes C, Nogueira C. 2014. Cervical extradural haematoma in an ataxic horse. Equine Vet Educ 26, 306-309.

Crempien C. 1988. Deficiencia de selenio en ovinos. Investigación y Progreso Agropecuario (IPA), INIA, La Platina 47, 33-34

Denoix JM. 2005. Thoracolumbar malformations or injuries and neurological manifestations. Equine Vet Educ 17, 191-194.

Denoix JM. 2007. Discovertebral pathology in horses. Equine Vet Educ 19, 72-73.

Denoix JM, Audigié F, Coudry V. 2005. A review of diagnosis and treatment of lumbosacral pain in sport and racehorses. AAEP Proceedings 51, 366-373.

Derouen A, Spriet M, Aleman M. 2016. Prevalence of anatomical variation of the sixth cervical vertebra and association with vertebral canal stenosis and articular process osteoarthritis in the horse. Vet Radiol Ultrasound 57, 253-258.

Dörner C, Uzal F, Carvallo F, Palmero J. 2015. Compressive myelopathy caused by epidural haemotoma associated with fibrocartilaginous embolism in a horse. Equine Vet Educ 27, 405-409.

Dyson S, Bulsoni V, Salciccia A. 2020. Intervertebral disc disease the cervical and craneal thoracic vertebrae in equine: eight cases. Equine Vet Educ 32, 437-443.

Furr MO, Anver M, Wise M. 1991. Intervertebral disk prolapsed and diskospondylitis in a horse. J Am Vet Med Assoc 198, 2095-2096. 
Gough S, Anderson J, Dixon J. 2020. Computed tomographic cervical myelography in horses: Technique and findings in 51 clinical cases. $J$ Vet Intern Med 34, 2142-2151.

Grant B, Paterson J. 2006. How to perform a myelogram in less than 30 minutes. AAEP Proceedings 52, 74-77.

Hahn C, Handel I, Green S, Bronsvoort M, Mayhew I. 2008. Assessment of the utility of using intra- and intervertebral minimum sagittal diameter ratios on the diagnosis of cervical vertebral malformation in horses. Vet Radio Ultra 49, 1-6.

Henneke D, Potter G, Kreider J, Yeates B. 1983. Relationship between condition score, physical measurements and body fat percentage in mares. Equine Vet J 15, 371-372.

Hirsch J, Grant B, Linovitz R, Peppers R, Rantanen T. 2009. Diagnosis and surgical treatment of epidural neoplasm in two ataxic horses. Equine Vet Educ 21, 564-568.

Hung Son N, Duong Huyen N. 2019. Selenium in aninal nutrition: metabolic pathways and animal response. J Anim Sci Technol 96, 2-13.

Janes J, Garrett K, Mcquerry K, Pease A, William N, Reed S, et al. Comparison of magnetic resonance imaging with standing cervical radiographs for evaluation of vertebral canal stenosis in equine cervical stenotic myelopathy. Equine Vet J 46, 681-686.

Janes J, Garrett K, Mcquerry K, Waddell S, Voor M, Reed S, et al. 2015. Cervical vertebral lesions in equine stenotic myelopathy. Vet Pathol 52, 919-927.

Johnson P, Johnson G, Pace L. 1997. Thoracic vertebral malformation in two horses. Equine Vet J 29, 493-496.

Kühnle C, Fürst A, Ranziger E, Sánchez-Andrade J, Kümmerle J. 2018. Outcome of ventral fusion of two or three cervical vertebrae with a locking compression plate for the treatment of cervical stenotic myelopathy in eight horses. Vet Comp Orthop Traumatol 31, 356-363.

Lerner D, Riley G. 1978. Congenital kyphoscoliosis in a foal. J Am Vet Med Assoc 172, 274-276.

Levine J, Ngheim P, Levine G, Cohen N. 2008. Associations of sex, breed, and age with cervical vertebral compressive myelopathy in horses: 811 cases (1974-2007). J Am Vet Med Assoc 233, 1453-1458.

Levine J, Scrivani P, Divers T, Furr M, Mayhew J, Reed S, et al. 2010. Multicenter case-control study of signalment, diagnostic features, and outcome associated with cervical vertebral malformationmalarticulation in horses. J Am Vet Med Assoc 237, 812-822.

Maldonado M. 2006. Contenido de nutrientes y metales pesados en suelos acondicionados con biosólidos, en experiencia de terreno y de laboratorio. Memoria de título. Universidad de Chile, Santiago, Chile.

MacMillan K, Bourque A, Perry L, Stoughton W. 2020. Acute nonambulatory tetraparesis in a 6-month-old Standardbred weanling caused by a cervical vertebral epidural haematoma. Equine Vet Edu 33, 293-296.

Matthews H, Nout Y. 2004. Spinal cord, vertebral and intracranial trauma. In: Reed S, Bayly W, Sellon D (eds). Equine Internal Medicine. Philadelphia: D.C. Saunders, Pp 566-579.

Mayhew I, Watson A, Heisa J. 1978. Congenital occipitoatlantoaxial malformations in the horse. Equine Vet J 10, 103-113.

Moore B, Reed S, Robertson J. 1993. Surgical treatment of cervical stenotic myelopathy in horses: 73 cases (1983-1992). J Am Vet Med Assoc 203, 108-112.

Murúa JC. 2006. Evaluación del desempeño deportivo de caballos criollos chilenos en el rodeo chileno amansados por doma racional o doma tradicional. Memoria de título. Universidad Austral de Chile, Valdivia. Chile.

Nixon A, Stashak T, Ingram T, Norrdin R, Park R. 1984. Cervical intervertebral disk protrusion in a horse. Vet Surg 13, 154-158.

Nixon AJ. 1991. Surgical management of equine cervical vertebral malformation. Prog Vet Neurol 2,183-195.

Nout YS, Reed SM. 2003.Cervical vertebral stenotic myelopathy. Equine Vet Edu 15, 212-223.

Oswald J, Love S, Parkin T, Hughes K. 2010. Prevalence of cervical vertebral stenotic myelopathy in a population of thoroughbred horses. Vet Rec 166, 82-83.

Perris E, Reed S, Partington B, Getzy D. 1994. A block vertebra in an equine patient. $J$ Equine Vet $S c i$ 14, 664-667.

Pezzanite L, Easley J, Bayless R, Aldrich E, Nelson B, et al. 2021. Outcomes after cervical vertebral interbody fusion using an interbody fusion device and polyaxial pedicle screw and rod construct in 10 horses (2015-2019). Equine Vet $J$ doi: 10.1111/evj.13449.

Piercy R. 2011. Cervical stenotic myelopathy. In: Ross M, Dyson S (eds). Diagnosis and Management of Lameness in Horse. W.B. Saunders, St. Louis, USA, Pp 649-654.

Reed S, Grant B, Nout Y. 2007. Cervical vertebral stenotic myelopathy. In: Furr M, Reed S (eds). Equine Neurology. Blackwell Publishing, Iowa, USA, Pp 283-298.

Rendle D, Durham A, Bestbier M, Smith K, Boswell J. 2008. Neurenteric cyst with associated butterfly vertebrae in a seven-month-old colt. Vet Rec 162, 558-562.

Rooney JR. 1969. Disorders of the nervous system In: Rooney JR (ed). Biomechanics in lameness. Williams and Wilkins, Baltimore, USA, Pp 219-233.

Rush B. 2012. Developmental vertebral anomalies In: Auer J, Stick J. editors. Equine Surgery, Philadephia: W.B. Saunders, p 693-699.

Sebastian M, Giles R. 2004. Fibrocartilaginous embolic myelopathy in a horse. $J$ Vet Med A 51, 341-343.

Stewart R, Reed S, Weisbrode S. 1991. Frequency and severity of osteochondrosis in horses with cervical stenotic myelopathy. Am $J$ Vet Res 52, 873-879.

Szklarz M, Lipinska A, Slowikowsa M, Niedzwied A, Marycz K, et al. 2019. Comparison of the clinical and radiographic appearance of the cervical vertebrae with histological and anatomical findings in an eight-month old warmblood stallion suffering from cervical vertebral stenotic myelopathy (CVSM). BMC Vet Res 15, 296.

Tapia J. 2013. Balance metabólico nutricional de selenio y variaciones estacionales de glutatión peroxidasa en equinos de la zona sur de Chile entre los años 2004 a 2011. Memoria de Titulo, Universidad Austral de Chile, Valdivia, Chile.

van Biervliet J, Mayhew J, de Lahunta A. 2006. Cervical vertebral compressive myelopathy: diagnosis. Clin Tech Equine Pract 5, 54-59.

Watson A, Mayhew I. 1986. Familial congenital occipitoatlantoaxial malformation (OAAM) in the Arabian horse. Spine 11, 334-339.

Witte S, Alexander K, Bucellato M, Sofaly C, Fife W, et al. 2005. Congenital atlantoaxial luxation associated with malformation of the dens axis in a Quarter Horse foal. Equine Vet Educ 17, 175-178.

Wong D, Scarratt W, Rohleder J. 2005. Hindlimb paresis associated with kyphosis, hemivertebra and multiple thoracic vertebral malformations in a Quarter Horse gelding. Equine Vet Educ 17, 187-191.

Zarczyñska K, Sobiech P, Radwiñska J, Rêkawek W. 2013. Effects of selenium on animal health. J Elem 2, 329-340. 
